\title{
New directions for inline inspection of automobile laser welds using non-destructive testing
}

\author{
Miguel Araújo Machado ${ }^{1}$ (D) - Luís Filipe Soldado Granadeiro Rosado ${ }^{2,3}$ (D) Nuno Alberto Marques Mendes ${ }^{1}$ (D) \\ Rosa Maria Mendes Miranda ${ }^{1}$ (1D $\cdot$ Telmo Jorge Gomes dos Santos ${ }^{1}[$
}

Received: 5 July 2021 / Accepted: 2 September 2021 / Published online: 14 September 2021

(C) The Author(s) 2021

\begin{abstract}
An innovative pilot installation and eddy current testing (ECT) inspection system for laser-brazed joints is presented. The proposed system detects both surface and sub-surface welding defects operating autonomously and integrated with a robotized arm. Customized eddy current probes were designed and experimentally validated detecting pore defects with $0.13 \mathrm{~mm}$ diameter and sub-surface defects buried $1 \mathrm{~mm}$ deep. The integration of the system and the manufacturing process towards an Industry 4.0 quality control paradigm is also discussed.
\end{abstract}

Keywords Non-destructive testing · Eddy current testing · Laser brazing welding · Automotive industry $\cdot$ Inline inspection . Industry 4.0

\section{Introduction}

Laser brazing has become a key process for sheet metal joining in the automotive industry. It is nowadays widely used, and the standard process to replace the conventional roof drip moulding. When compared with the result of alternative processes, laser brazing joint performance is considerably superior introducing advantages such as higher car body stiffness, smoother car design, reliable weld bead for 3D contours, low heat input and distortion, no additional sealing, high speed/ productivity and low cost [1]. Laser brazing joints are also ductile, leak proof and robust [2].

One of the major advantages is the low heat input, and thus, the welded parts' low thermal distortion, which is hard to achieve with conventional fusion welding. In addition, laserbrazed joints exhibit very high-quality surfaces, and the

Miguel Araújo Machado

miguel.m@ fct.unl.pt

1 UNIDEMI, Department of Mechanical and Industrial Engineering, NOVA School of Science and Technology, NOVA University Lisbon, 2829-516 Caparica, Portugal

2 Instituto de Telecomunicações, Lisbon, Portugal

3 Instituto Superior Técnico, Universidade de Lisboa, Lisbon, Portugal process can be fully automated. Due to these unique properties, it is widely used in car body manufacturing, especially on visible joints on the roof, Fig. 1, and tailgates [3]. The most common filler material is silicon bronze $(\mathrm{CuSi3})$. Despite the advantages over alternative processes, several types of weld imperfections may appear in the produced joints.

The imperfections relate to metallurgical reactions with the base metals unintentionally melting or to the formation of brittle intermetallic compounds [4]. There are three different basic types of weld imperfections, which may appear in various sizes and morphologies, specifically (i) occurrence of pores, with different dimensions and isolated or as clusters; (ii) joint disruptions in the shape of large cavities, discontinuities, lack of bonding and one-sided wetting; (iii) surface irregularities in the form of scaly or wavy seam surfaces, also including surfaces with protruding bits of non-fused brazing wire. Acceptance criteria for laser welds may be established under the DIN EN ISO 13919-1.

On most of the factory installations, laser-brazed welding assessment is essentially performed by human visual inspection and destructive testing. Visual inspection applies to all the produced chassis while destructive testing is performed to randomly selected units $(<1 \%$ of the production) and over units exhibiting potential issues after visual inspection. Destructive testing applied relies on the joint section macro and micrographic analysis performed with 10 to $20-\mathrm{mm}$ spacing over the weld length. It is time consuming and expensive. 
Fig. 1 Laser-brazed weld joints sealing a car roof (weld seam marked with the red arrows)

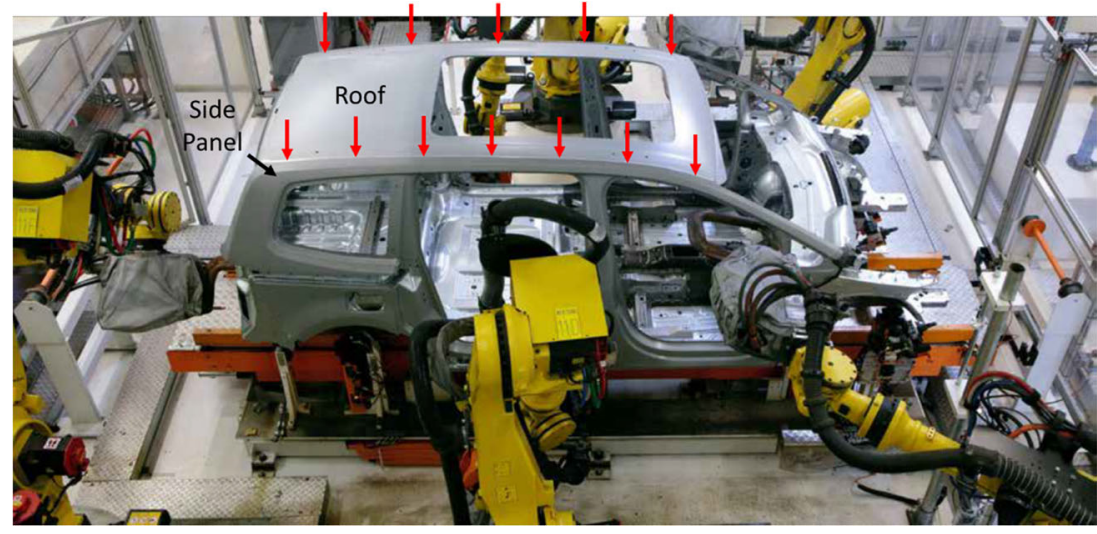

\subsection{Non-destructive testing for laser-brazed welding}

Several non-destructive testing (NDT) solutions were tried, amongst them, the laser triangulation technique. With this technique, it is possible to gain information about the brazed surface morphology and height while measuring light reflection. An algorithm processes the profile in 3 dimensions, enabling the surface defects' detection. However, the technique is limited to low speed inspections, to surface defects and to the detection of defects whose dimension is high enough for their naked eye detection $[5,6]$.

Other possible inspection strategy is to use image processing for the defect's detection and classification while combining multiple images captured from the brazed surface. Unlike laser triangulation, the method does not provide a 3 dimensional weld profile, relying on an approach close to a visual inspection. The main disadvantages are the lack of precision, low inspection speed and especially the necessary hardware high cost $[5,7]$.

Recently, a laser-brazed weld inspection system combining the two previously discussed approaches was proposed, enhancing the inspection accuracy and increasing speed and efficiency [5]. The principle of triangulation is used to control the joint overall quality while dedicated image processing algorithms allow detecting surface pores. Nevertheless, shortcomings as the high implementation cost and the impossibility of detecting relevant subsurface defects materialize. Moreover, image processing algorithms are performed offline as a post-process.

Industrial inline quality control systems are highly desired to answer laser-brazed welding quality requirements and overcome offline inspection efficiency limitations [8-13]. For this purpose, several commercially available NDT inspection technologies may be considered. Table 1 discusses the applicability and summarizes the main limitations of different market available potential alternatives.

In contrast with other methods on Table 1, the eddy current testing (ECT) method is close to answer the main requirements for laser-brazed welding inline quality control. The method can detect surface and sub-surface defects using customized probes for different inspection scenarios. Besides this, results tend to be easily read/processed and inspections can be completely automated. However, given the inspection situation and the concerning requirements, commercial solutions are not yet available. The design, production and validation of a dedicated laser-brazed welding ECT inspection system is therefore necessary. The automotive industry has very demanding requirements, not possible to assure by existing commercial eddy current NDT solutions, namely:

- Distinguish between surface and internal defects

- Detection of defect sizes below $0.25 \mathrm{~mm}$

- Intensive use and wear resistance

- High SNR to assure high reliability in detection

We developed a customized solution, optimized for the geometry, material properties and the defects' location and morphology of automobile laser-brazed joints.

\section{Innovative eddy current testing (ECT) inspection system}

The following sections describe the developed ECT inspection system, providing details on the customized probe, the scanning device as well as the robotic inspection pilot installation used for experimental demonstration.

\subsection{Laser-brazed welding geometrical and material characterization}

The weld is performed over two parts, the side and roof steel panels, and a filler material. The involved materials' electrical conductivity was assessed by the potential drop measurement technique [14] using a commercial four-point probe with $0.635 \mathrm{~mm}$ pin spacing. This information, crucial for the design of customized EC probes, is presented in Table 2. 
Table 1 Applicability and limitations of commercial NDT methods

\begin{tabular}{|c|c|c|}
\hline NDT method & Applicability & Observations and limitations for automotive industry \\
\hline $\mathrm{X}$-ray & Limited/incomplete & $\begin{array}{l}\text { - Complex geometry or non-orthogonality to the radiation direction. } \\
\text { - Integration tends to be complex (need of accessing both sides of the joint), time consuming. } \\
\text { - Operator's safety issues due to radiation exposure. }\end{array}$ \\
\hline Ultrasounds & Limited/impossible & $\begin{array}{l}\text { - Complex geometry and non-flat surface is a difficulty to the probe coupling. } \\
\text { - The curvature between the probe coupling and the brazed zone results on a complex and non-unique echo } \\
\text { condition, seriously compromising the inspection. } \\
\text { - Low-thickness chassis sheets introduce difficulties to stimulate longitudinal ultrasound waves. }\end{array}$ \\
\hline $\begin{array}{l}\text { Dye } \\
\text { penetrants }\end{array}$ & Reduced/incomplete & $\begin{array}{l}\text { - Applies to surface defects only. } \\
\text { - Extremely difficult to automate. }\end{array}$ \\
\hline $\begin{array}{l}\text { Eddy } \\
\text { currents }\end{array}$ & Possible & $\begin{array}{l}\text { - Sensible to positioning and lift-off. } \\
\text { - Sensitivity is affected by electrical conductivity and magnetic permeability. } \\
\text { - Defects far from the surface may not be detected. } \\
\text { - Missing availability of dedicated commercial probes. }\end{array}$ \\
\hline
\end{tabular}

The standard depth of penetration (SDP) corresponds to the depth at which the eddy current density is less than $37 \%$ of the surface EC density generated in a homogenous and isotropic material part. Due to the physical nature of EC, this depends on the frequency used, the material magnetic permeability and its electrical conductivity [15]. Being the magnetic permeability and electric conductivity intrinsic to the material, the option to change the penetration depth relies on the operation frequency. The standard depth of penetration on the filler material was computed in Table 3 for some illustrative frequencies, according to Eq. 1 [16], where $\delta(\mathrm{mm})$ is the SDP, $f(\mathrm{~Hz})$ is the frequency, $\mu_{\mathrm{r}}=\mu /$ $\mu_{0}(-)$ is the relative magnetic permeability and $\sigma(\%$ IACS) is the electrical conductivity.

$\delta=\frac{661}{\sqrt{\pi f \mu_{r} \sigma}}$

Considering: magnetic permeability $\mu=\mu_{0}=4 \pi \times 10^{-7}$ $[\mathrm{H} / \mathrm{m}]$ (or $\mu_{\mathrm{r}}=1$ - nonferromagnetic) and electric conductivity $\sigma=2.03 \times 10^{6}(\mathrm{~S} / \mathrm{m})(3.5 \%$ IACS $)$

\subsection{Eddy current probe design}

\subsubsection{Conceptual solution}

Conventional EC coils/probes (cylindrical helical probes with ferrite cores, often called pencil probes) have a recognized ability to identify porosity and surface/sub-surface crack defects as well as to provide contactless electrical conductivity measurements [17]. With the correct probe geometry and inspection parameter choice, the whole bead profile may be inspected. Due to the parts and weld bead geometry, a very small opening for the probe to reach the bead surface is available (Table 3). To enhance sensitivity, the probe tip must contact the weld bead surface, thus introducing a constraint to the probe diameter. Provided the small dimensions of the weld bead surface, dedicated EC coils were designed and produced.

Aiming at the detection of both defects and low-gradient metallurgical changes (arising from the laser brazing process deviations), an absolute EC measurement was chosen over the differential option [17]. Yet, to enhance sensitivity, a bridge circuit including an additional compensation/reference coil was used, Fig. 2.
Table 2 Electrical resistivity and conductivity measured with a potential drop probe

\begin{tabular}{llllll}
\hline Part & $\begin{array}{l}\text { Material (alloys not specified due to } \\
\text { confidential agreements) }\end{array}$ & Permeability & Resistivity & \multicolumn{2}{c}{ Conductivity } \\
\cline { 4 - 6 } & & $\mu / \mu_{0}$ & $\Omega \mathrm{m}$ & $\mathrm{S} / \mathrm{m}$ & $\%$ \\
& & $\gg 1$ & $1.92 \times 10^{7}$ & $5.21 \times$ & 8.9 \\
Roof & Steel alloy & & & $10^{6}$ & \\
Side panel & Steel alloy & & $1.55 \times 10^{7}$ & $\begin{array}{r}6.44 \times \\
10^{6}\end{array}$ & 11.1 \\
Filler material & Copper alloy & $\approx 1$ & $4.93 \times 10^{7}$ & $2.03 \times$ & 3.5 \\
& & & & $10^{6}$ & \\
\hline
\end{tabular}


Table 3 Standard depth of penetration in the filler material

\begin{tabular}{|c|c|c|}
\hline Frequency [kHz] & Penetration depth [mm] & Profile macro \\
\hline 100 & 1.117 & \\
\hline 250 & 0.706 & \\
\hline 500 & 0.500 & \\
\hline 750 & 0.408 & \\
\hline 1000 & 0.353 & \\
\hline 2000 & 0.250 & \\
\hline 3000 & 0.204 & \\
\hline
\end{tabular}

Provided the bridge circuit symmetry and positioning the reference coil over a sound weld, this coil generates an $\vec{U}_{\mathrm{r}}$ signal similar to that expected on $\vec{U}_{\mathrm{i}}$ when the inspection coil overlaps a sound weld. Measuring $\vec{U}_{\text {out }}$ as the difference between $\vec{U}_{\mathrm{i}}$ and $\vec{U}_{\mathrm{r}}$, allows subtracting/cancelling the baseline signal and therefore increase the applied analog amplification gain. As such, the ECT instrument explored dynamic range is maximized, resulting in an enhanced signal-to-noise ratio and a lower defect detectability limit.

\subsubsection{Numerical simulation}

Numeric simulations were performed to assist the ECT probe design and understand the concerning electromagnetic phenomena in the weld bead geometry and materials. A numerical simulation software (ANSYS Electronics) was used to calculate an approximate numerical solution of Maxwell's equations in their full formulation, finite integration technique (FIT). A CAD model was designed starting from a digitalized weld bead profile macro, to be as similar as possible to the real one. The material properties were set according to the measured properties in Table 2. The joint CAD model and the probe components are depicted in Fig. 3a. The coil is modelled as a copper sleeve and defined as a winding which is composed of 200 conductors, with $1 \mathrm{~mm}$ outer diameter, $0.7 \mathrm{~mm}$ inner diameter and $2 \mathrm{~mm}$ height. The distance between the probe and the weld bead (lift-off) was set to $0.2 \mathrm{~mm}$ and an alternated current of $1 \mathrm{~A}$ was imposed. The coil is wound over a ferrite core to increase the magnetic field density. A ferrite shield with $2 \mathrm{~mm}$ outer diameter is also included, further confining the magnetic field on the weld bead and reducing the generation of EC in the chassis panels, which are not the inspection target. Fig. $3 \mathrm{~b}$ depicts the model used and the applied tetrahedral mesh representation containing about $1 \mathrm{M}$ elements.

The EC in-depth profile depends on both the probe geometry and the operation frequency [18]. Fig. 4 depicts the EC density on the weld bead when the coil is excited with $250 \mathrm{kHz}$ and $2 \mathrm{MHz}$ frequencies. When operating at the lowest frequency, Fig. 4a, EC remains mostly confined on the weld bead and extends along most of its depth. In opposition, for the $2 \mathrm{MHz}$ frequency, Fig. 4b, the eddy current density remains mostly superficial. It can be concluded that the use of
Fig. 2 Proposed ECT probe configuration: (a) CAD representation; (b) readout circuitry

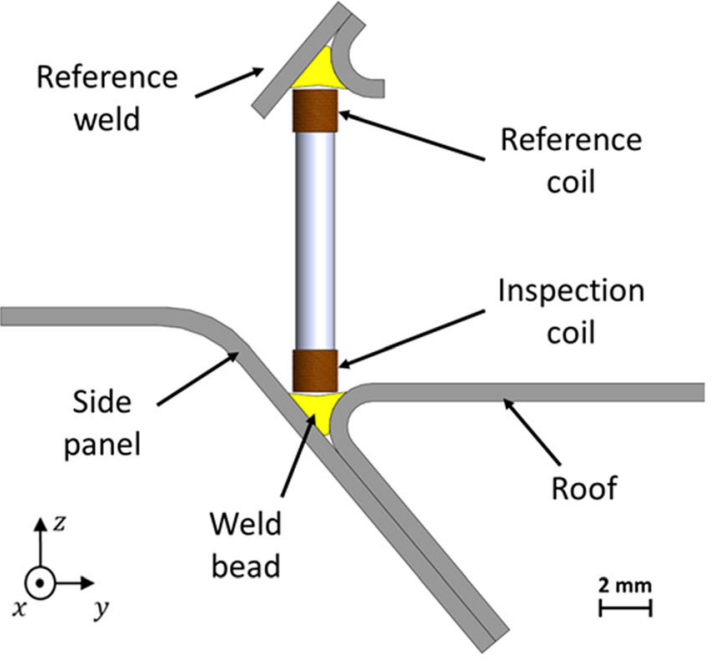

a)

b)

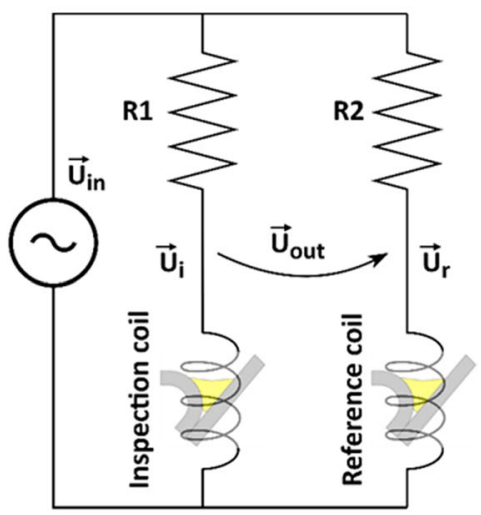



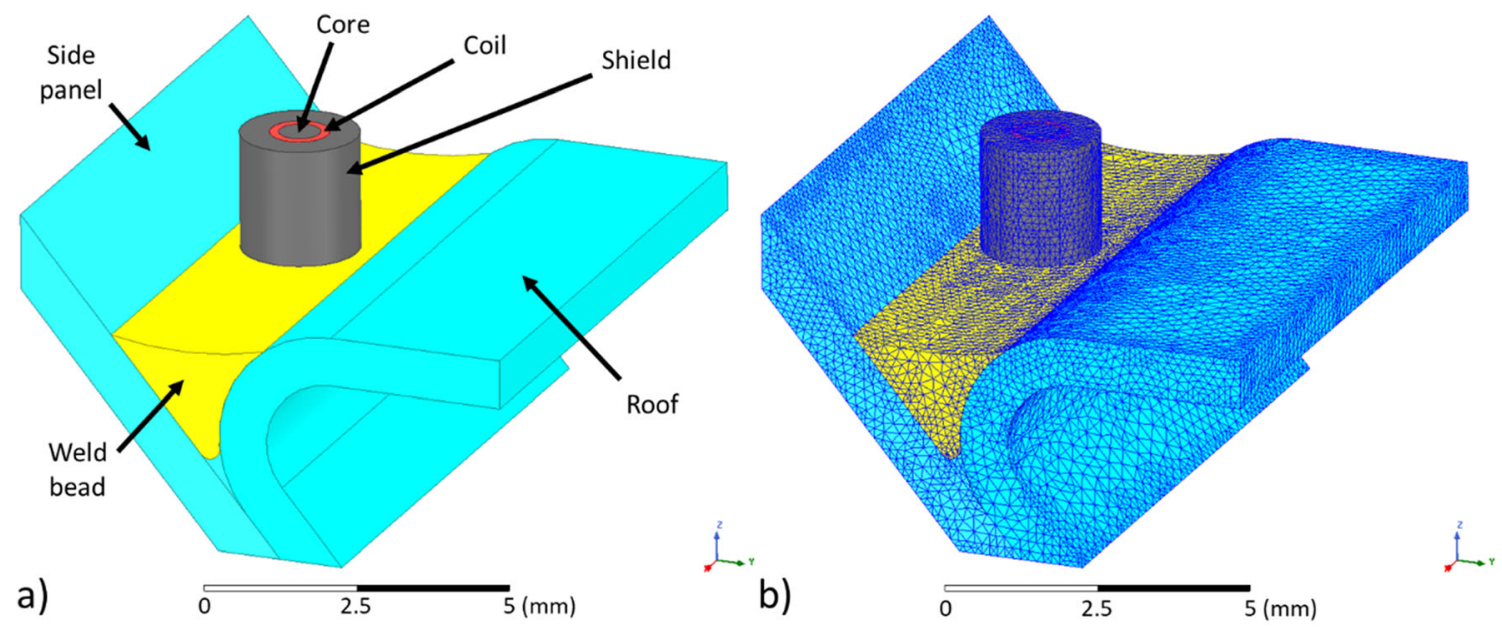

Fig. 3 Numerical simulation model: (a) CAD representation; (b) mesh representation with the tetrahedral elements

lower frequencies allows detecting both surface and subsurface defects; results from different frequencies allow to resolve the defects' depth/location.

\subsubsection{Eddy current probe production}

Reduced diameter bobbin coils were tailor-made to fit the weld bead surface. Besides this design decision, the number of windings was chosen to maximize the generated magnetic field, bearing in mind the limitations imposed by the bridge excitation circuit. Each bobbin coil produced was thoroughly characterized with numerous frequency sweeps on distinct materials with different electrical conductivities and lift-offs. The characterization allowed to find the best combinations for the desired purpose. The used bobbin coils have $2 \mathrm{~mm}$ outer diameter and $1.65 \mathrm{~mm}$ height whereas the weld bead profile has around $2.3 \mathrm{~mm}$ width. The probes with the best performance comprised 200 windings of $40 \mu \mathrm{m}$ diameter wire.

A probe holder was designed and produced to assemble the coils together, Fig. 5. An encapsulated probe is depicted in

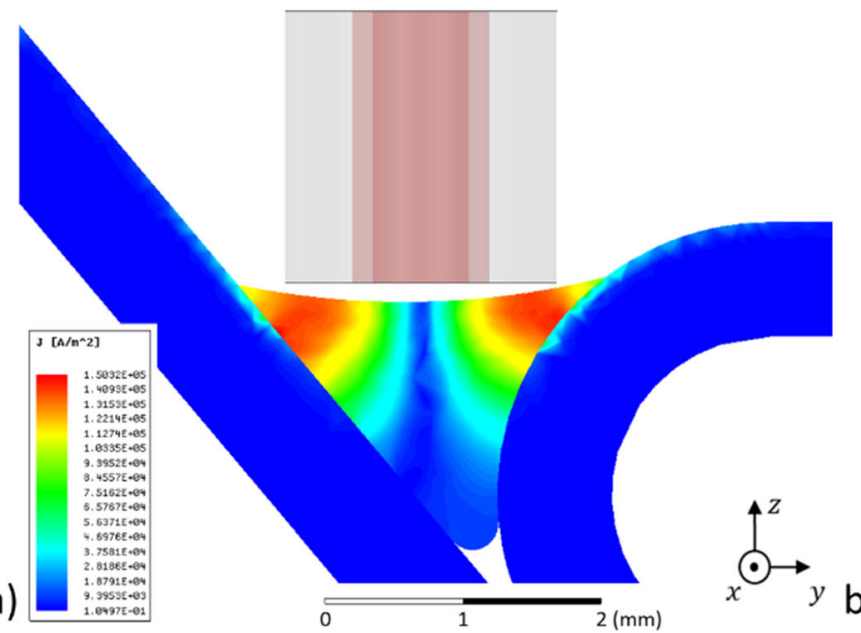

Fig. 4 ECT numerical simulation with frequency: (a) $250 \mathrm{kHz}$; (b) $2 \mathrm{MHz}$
Fig. 5a while the coils' full assembly is shown in Fig. 5b. This assembly is attached to the scanning device chassis by a linear bearing while a spring ensures a close to constant and reduced lift-off.

\subsection{Scanning device prototype}

The EC probe movement is performed by a robotic arm, to ensure the correct probe positioning throughout the inspection, a scanning device was developed. This device carries the probe while being coupled to the robotic arm moving along the joint. Three wheels allow a rolling movement aligned with the weld bead. Two wheels will roll over the bead like train wheels over tracks, guiding the device during the scan. With this solution, any small imprecise robot trajectory can be tolerated.

The weld profile uniformity was evaluated along the full chassis length. Several section profiles were taken from a complete $3 \mathrm{~m}$ weld sample later used to recreate 3D models. The weld bead uniformness was evaluated overlapping the 3D

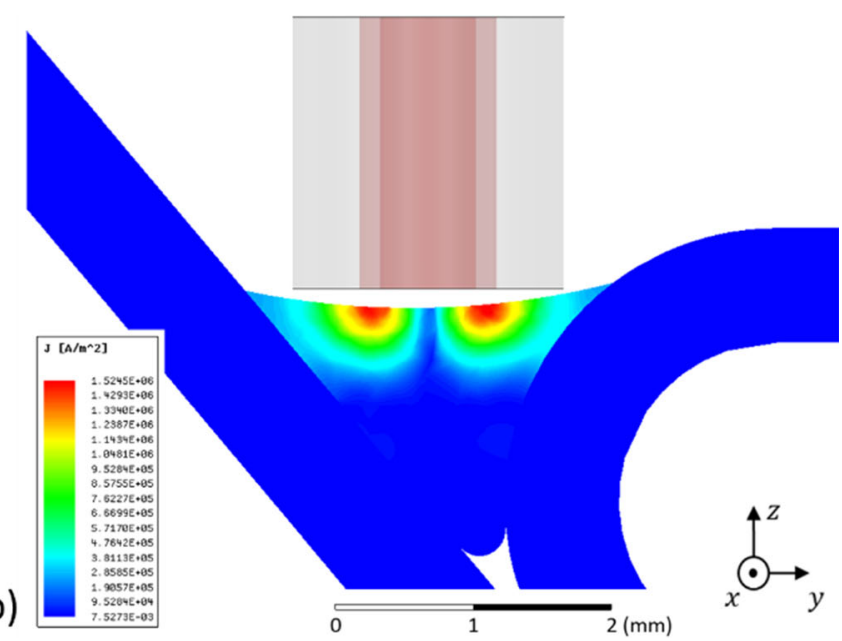




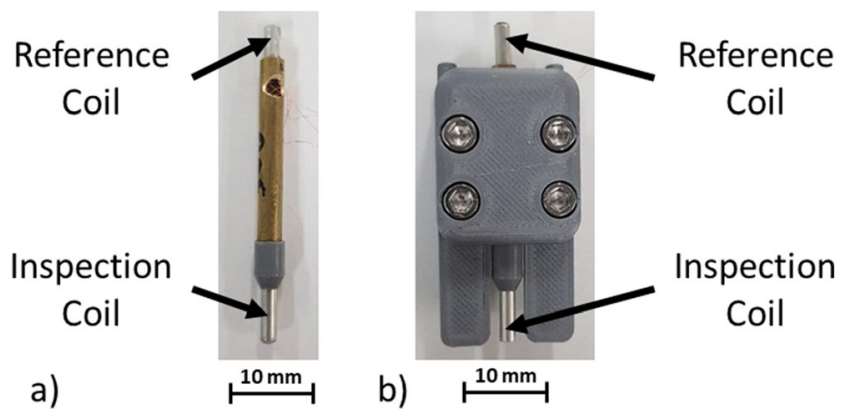

Fig. 5 Tailored EC probes. (a) EC probe with the inspection and reference coils; (b) EC probe assembled in its chassis

models as shown in Fig. 6a. The zone with most variation corresponds to the position of the rear wheel, about $2.5 \mathrm{~mm}$. As observed in Fig. 6b, the variation in the probe zone is pretty much inexistent and considered not significant from the point of view of the chassis coupling.

The prototype was produced using fused deposition modelling (FDM) 3D printing as it allows fast, cost effective and easy customization. It also enables the production of units targeting the final deployment [19]. Fig. 7 shows the scanning device used to perform the inspection in real environment which is then coupled to a robotic arm.

\subsection{Robotic inspection pilot installation}

A fully automated robotic inspection installation was built, Fig. 8. This installation comprises an industrial robot KUKA KR6 (to move the scanning device), the previously introduced EC probe (to inspect the brazing seam), an Olympus Nortec $600 \mathrm{D}$ digital ECT instrument (to excite and acquire the probe signals) and a computer (to run dedicated software for results display, storage and processing). Once a new part is positioned in the inspection site, the robot arm moves to position the probe over the brazed seam. Then, the robot sends a TCP/
IP socket message, warning the computer software to trigger the acquisition, processing and storage of the inspection data. The ECT instrument is continuously operating the probe while providing digitalized signals through a serial communication port to the computer. Whenever a defect is detected from the ECT instrument data, the computer queries the robot concerning the current position. Once the robot finishes, it sends a message to the computer to halt the acquisition.

\section{Experimental validation}

\subsection{Experimental results with relevant defects}

Experimental tests were conducted with the pilot installation in industrial environment. An automobile chassis weld bead was inspected without prior knowledge of its condition. The ECT system was able to detect extremely small defects as notches with around 0.13 to $0.27 \mathrm{~mm}$ diameter. Figs. 9 to 12 show the inspection signal and the respective defect. The defects were detected exploring different frequencies $(250 \mathrm{kHz}$, $750 \mathrm{kHz}$ and $1 \mathrm{MHz}$ ), even though $250 \mathrm{kHz}$ showed enhanced signal-to-noise ratio (SNR). The scanning device was moved at a $0.4 \mathrm{~m} / \mathrm{s}$ speed sweeping several chassis while visual inspection of the signals allowed an easy identification of the defects.

The probe output signal was measured along the weld bead. In the absence of defects, the signal from the reference and the inspection coils $\left(\vec{U}_{\mathrm{r}}\right.$ and $\vec{U}_{\mathrm{i}}$ respectively) are very similar, resulting in near-zero impedance change. Once a defect is present, the EC distribution generated by the inspection coil will be modified, resulting in a change on this coil's magnetic field and consequently on its impedance. This impedance change causes a difference with the reference coil,

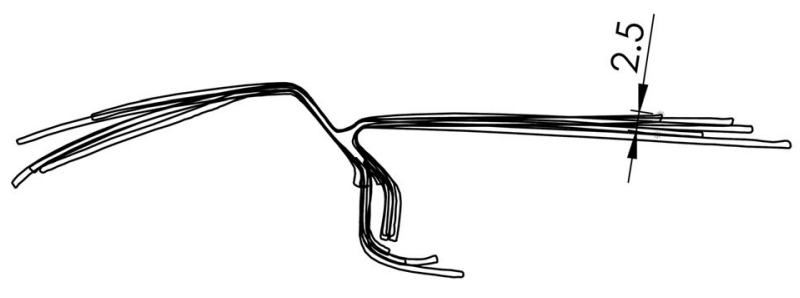

a)

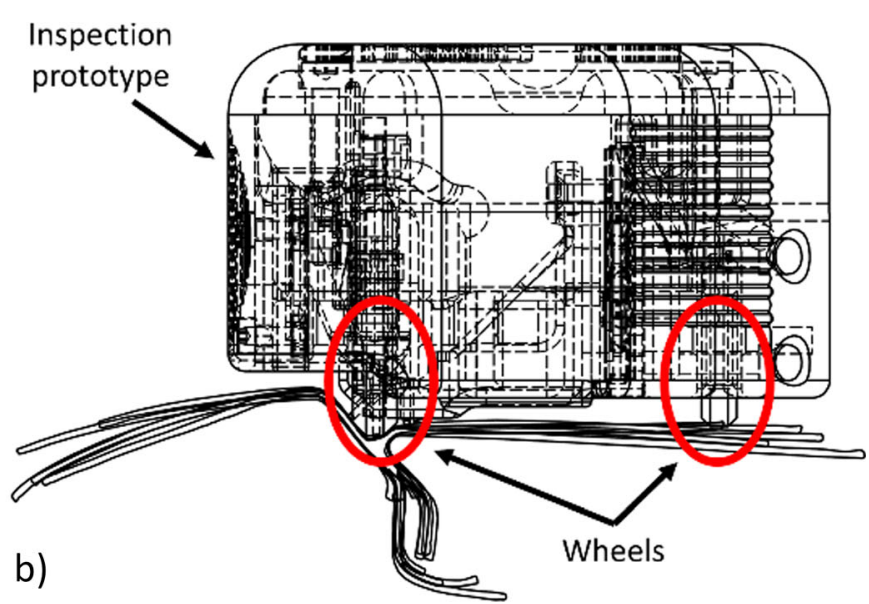

Fig. 6 Weld-profile uniformness along the chassis length. (a) Profiles at different locations overlapped to access its uniformness; (b) device positioned over the weld profile 
Fig. 7 Scanning device. (a) CAD representation; (b) prototype back view; (c) prototype bottom view a)
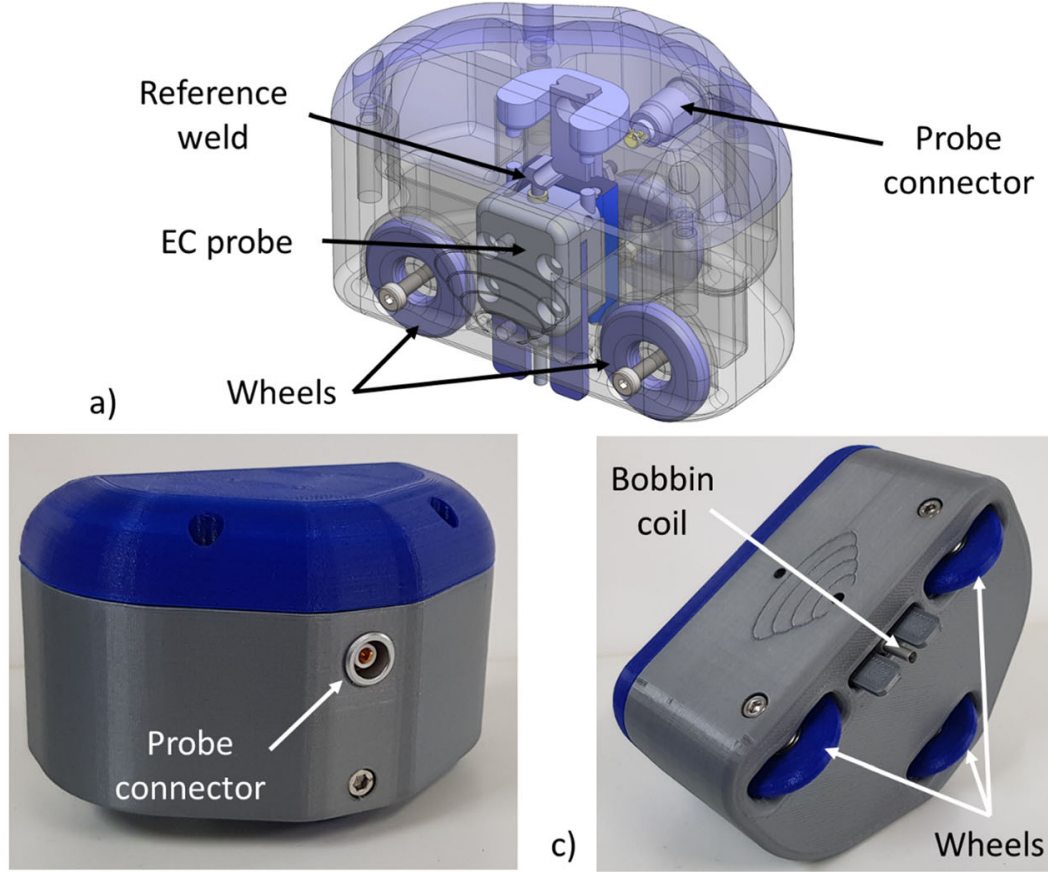

c)

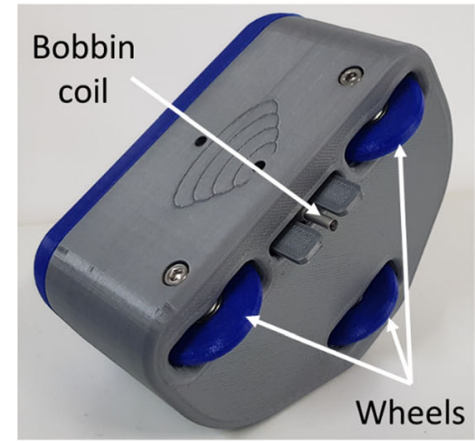

therefore unbalancing the bridge readout circuit (recall Fig. 2) while increasing the output signal amplitude.

Nevertheless, small signal variations are observed in the non-defective zones. These may be due to several different phenomena, namely: the material properties may change due to some material heterogeneity; the probe vibration, trajectory deviations or lift-off, corresponding to a small variation on the probe and the weld profile relative positioning; the electric noise due to electric cable movement.

These phenomena are very critical, special in the industrial environment, and can prevent the detection of sub-millimetre defects due to low SNR. That is why a customized solution must be developed to assure a good SNR and reliable inspection.

\subsection{Experimental results on artificial defects}

One of the established functional requirements is the ability to distinguish surface from sub-surface defects (defects that are below but not open to the weld surface). To meet this requirement, multiplexing of two different frequencies was employed during the inspection. The higher operation frequency aimed to target the detection of surface defects while the lower frequency has the potential of detecting defects deeper in the weld bead. To experimentally validate this capability, artificial defects were produced in a weld bead. The surface defects consisted of a $0.5 \mathrm{~mm}$ deep hole at the weld bead surface, made with a $1 \mathrm{~mm}$ drill bit (Fig. 13a). The sub-surface defects were drilled from the weld root without reaching the surface with a $1 \mathrm{~mm}$ drill (Fig. 13b).
Fig. 8 Robotic inspection pilot installation

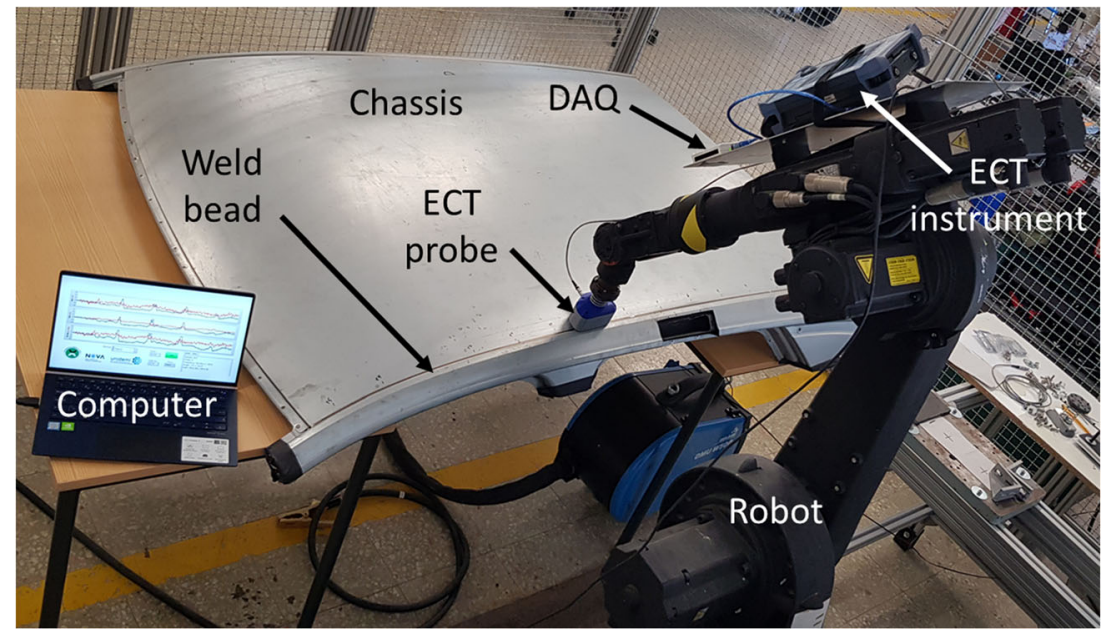



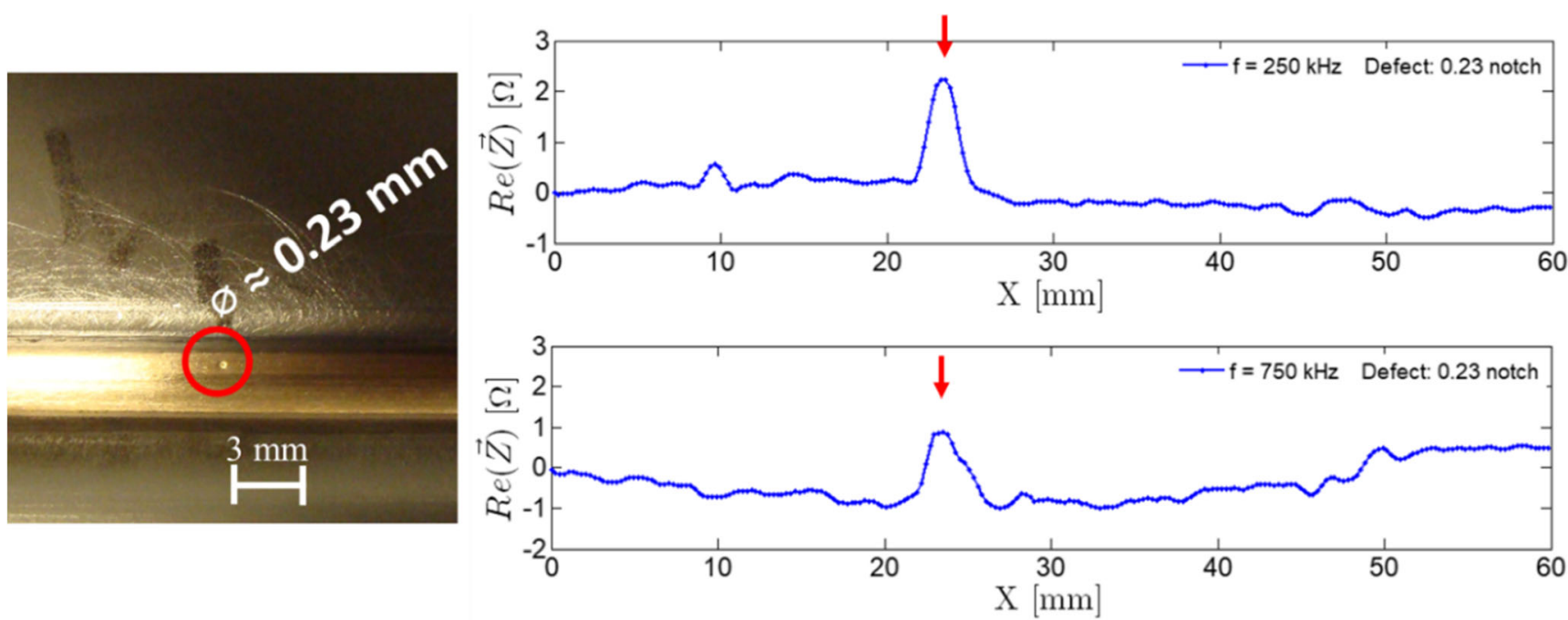

Fig. 9 Detection of a $0.23 \mathrm{~mm}$ diameter notch defect operating at 250 and $750 \mathrm{kHz}$ frequencies

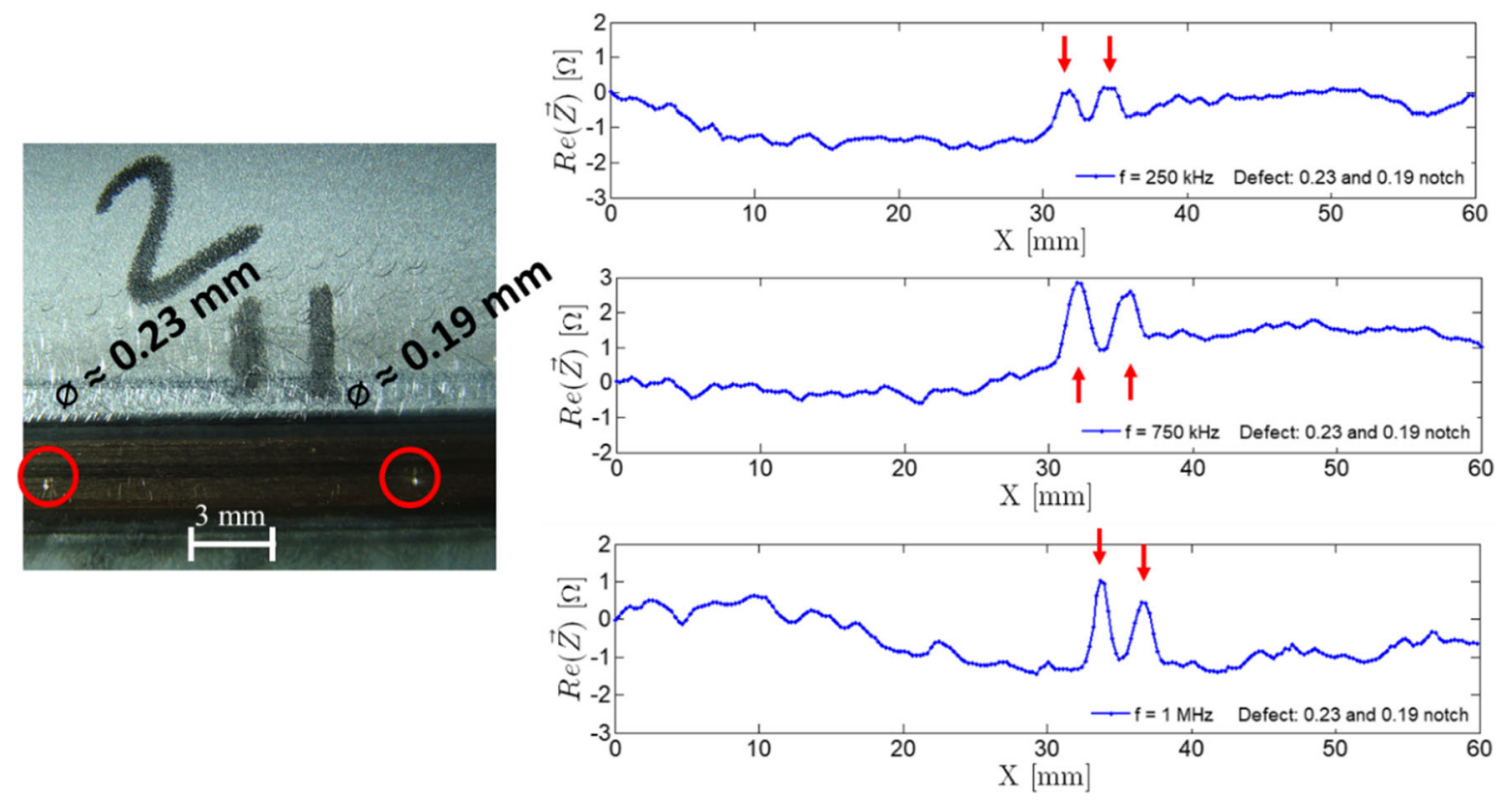

Fig. 10 Detection of two relevant notch defects, 0.23 and $0.19 \mathrm{~mm}$ diameters, operating at $250 \mathrm{kHz}, 750 \mathrm{kHz}$ and $1 \mathrm{MHz}$ frequencies

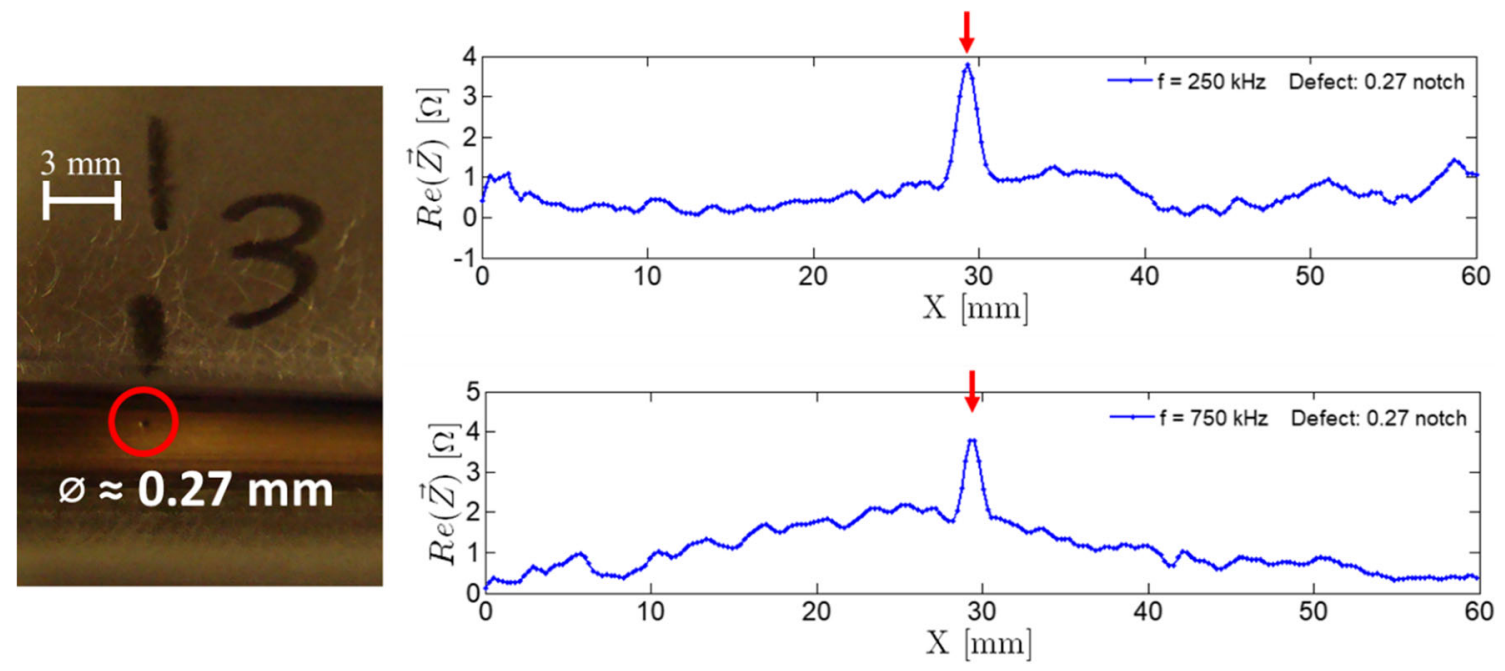

Fig. 11 Detection of a $0.27 \mathrm{~mm}$ diameter notch defect operating at 250 and $750 \mathrm{kHz}$ frequencies 

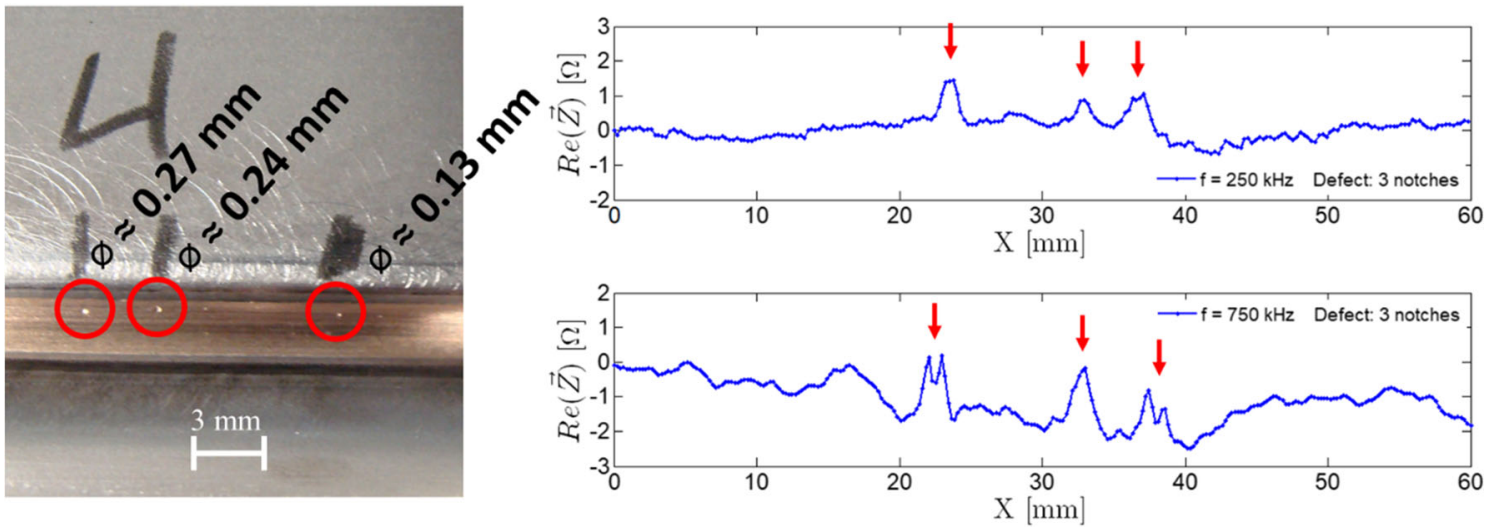

Fig. 12 Detection of three relevant notch defects operating at 250 and $750 \mathrm{kHz}$ frequencies

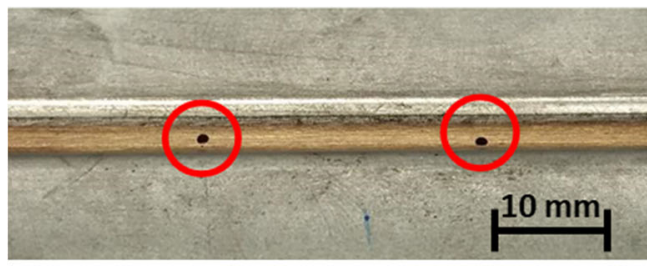

a)

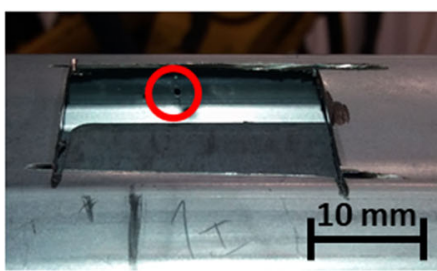

b)

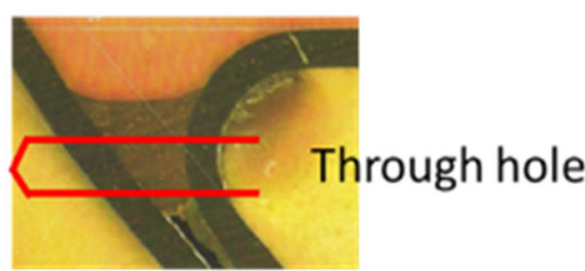

c)

Fig. 13 Artificial defects produced: a $1 \mathrm{~mm}$ diameter surface defects; $\mathrm{b}$ sub-surface defects, drilled from the side panel and crossing the weld bead; c schematic of the drilled hole

Fig. 14 Inspection signal obtained at high frequency (2 $\mathrm{MHz}$ ) and at low frequency (250 $\mathrm{kHz}$ )

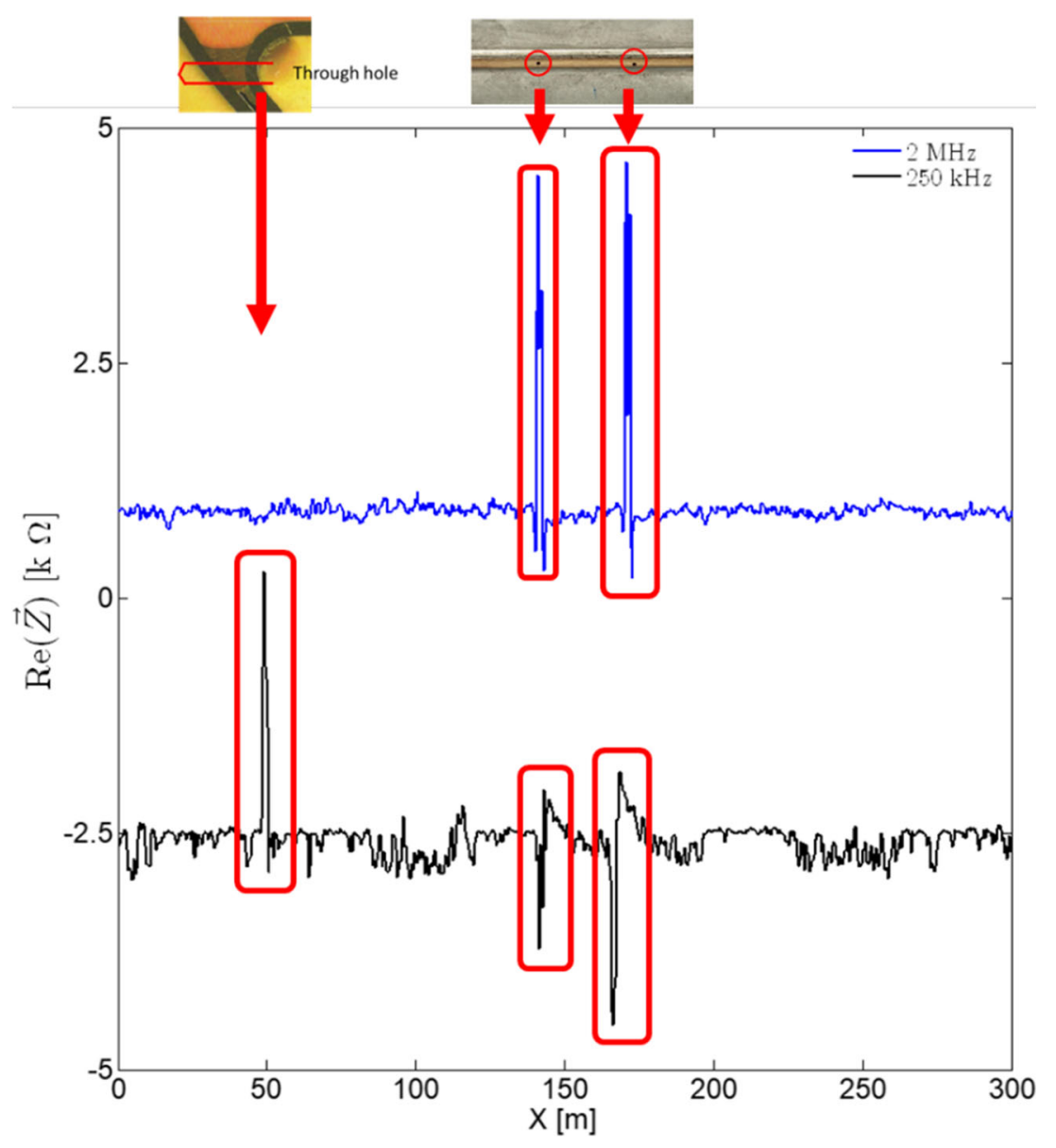


Fig. 14 shows the probe output when operating at the two selected frequencies. As observed, at $2 \mathrm{MHz}$ the inspection signal exhibits the response to the two artificial surface defects. Those can be clearly detected whereas the sub-surface defects originated no observable inspection signal response since the penetration depth is such that concentrates most of the eddy currents above. However, when operating at lower frequencies, $250 \mathrm{kHz}$, the sub-surface EC density increases, revealing the hidden defects. This difference between the inspection signal responses at two different frequencies can be used to distinguish between the two types of defects.

\section{New opportunities on the inspection of laser-brazed welding}

Besides ECT demonstrated benefits from a purely NDT perspective, the technique and the reported developments open new directions towards an Industry 4.0 compatible laserbrazed welding inspection. From a process integration perspective, ECT has demonstrated compatibility for inline automation and enables reaching an efficient full-coverage inspection. ECT instrumentation can be designed with the ability to control or synchronize with robotic arms and to report digital data over local networks and the internet (using both wired and wireless connectivity). The proposed integration of inline ECT inspection within the automotive laser brazing process is possible and it is shown in Fig. 15.

In this new inspection approach, data from both the manufacturing process and ECT feed a live database hosted over cloud resources. To fully profit from the inspection benefits, it is important to maximize the harvested data from the two sources. One possible selection of relevant data includes (although not limits to) the elements on Table 4.

Extended data gathered over successive chassis brings valuable information on the manufacturing process. With the growth of the database, Big Data analytics may reveal

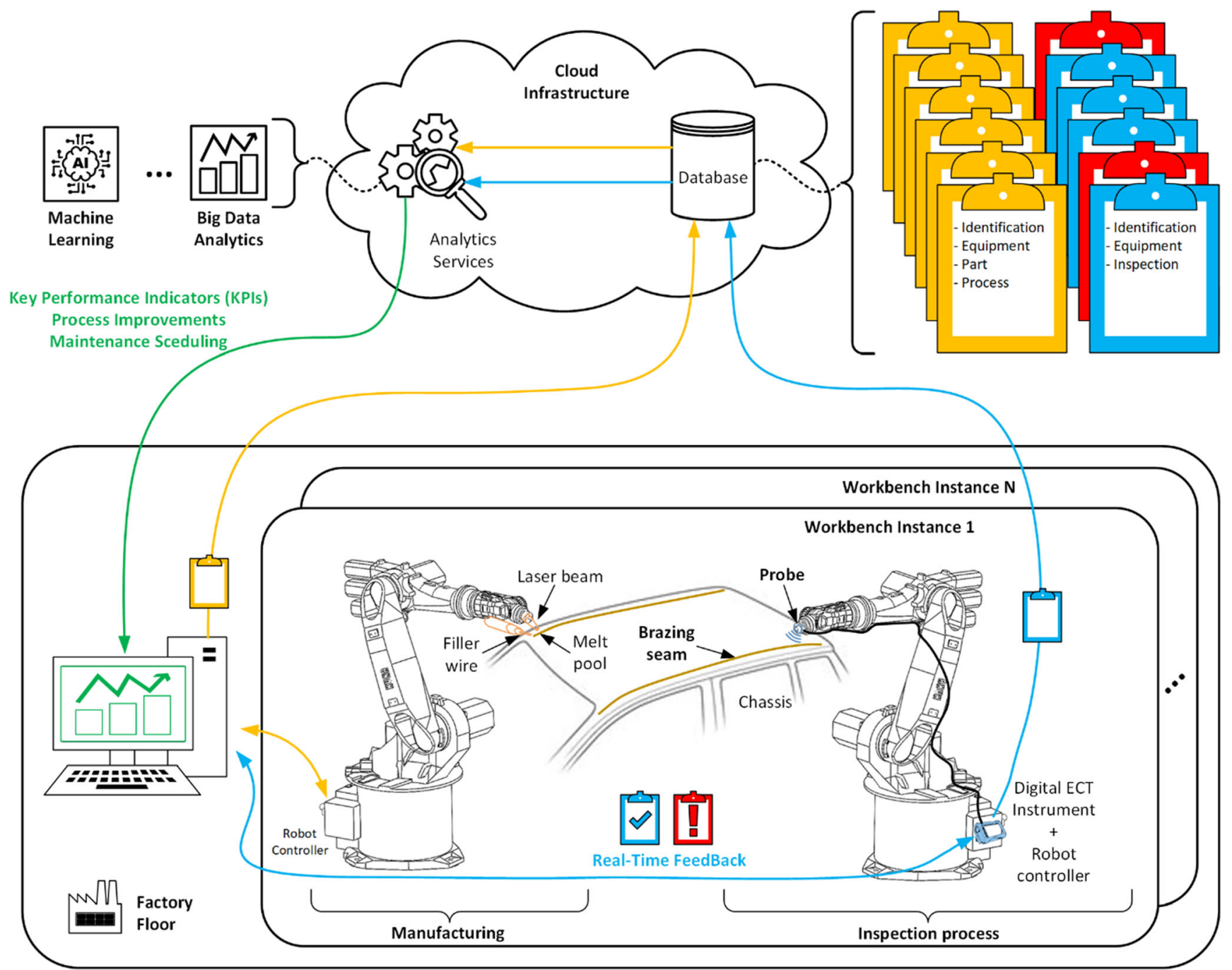

Fig. 15 Inline ECT inspection process integration 
Table 4 Relevant data on the laser-brazed welding and the inline ECT data

\begin{tabular}{ll}
\hline \multicolumn{2}{c}{ Manufacturing Process } \\
\hline \multirow{2}{*}{ Identification } & Vehicle Identifier Number (VIN) \\
\cline { 2 - 2 } Equipment & Begin timestamp \\
\cline { 2 - 2 } & \begin{tabular}{l} 
Welding robotic arm ID \\
\cline { 2 - 2 } Paser Source ID
\end{tabular} \\
\hline \multirow{3}{*}{ Feeder ID } \\
\hline \multirow{3}{*}{ Process } & $\begin{array}{l}\text { Materials (e.g. lot numbers) } \\
\text { previous manufacturing steps }\end{array}$ \\
\cline { 2 - 2 } & Laser power (target and \\
& measured if available) \\
\cline { 2 - 2 } & Laser Trajectory \\
\hline
\end{tabular}

previously unknown relations between the process parameters and the final welding quality and enable process improvements. From another perspective, machine learning techniques may be used to assist/schedule maintenance tasks while predicting the real state of the employed equipment. In addition, relevant key performance indicators (KPI) may be drawn.

Besides the mentioned outcomes, real-time analysis of the ECT data provide the needed process feedback to adjust to minor variations on the part and/or perform recovery actions over detected defective weld segments. This possibility gains relevancy when considering the integration of both the process and the inspection robotic arms cooperating in the same workbench.

Table 5 summarizes and highlights the advantages that the proposed ECT inspection system allows comparing to the traditional inspection procedures. Here, a comparison between the proposed and the original destructive testing approach is presented.

\begin{tabular}{|c|c|}
\hline & Inline ECT data \\
\hline \multirow{2}{*}{ Identification } & Vehicle Identifier Number (VIN) \\
\hline & Begin timestamp \\
\hline \multirow{3}{*}{ Equipment } & NDT Robotic arm ID \\
\hline & Instrument ID \\
\hline & Probe ID \\
\hline \multirow{5}{*}{ Inspection } & $\begin{array}{l}\text { Parameters (e.g. frequency, gains, } \\
\text { bandwidth, acquisition rate) }\end{array}$ \\
\hline & Probe trajectory \\
\hline & Raw data \\
\hline & $\begin{array}{l}\text { Pre-processed data (e.g., filtered, } \\
\text { normalized) }\end{array}$ \\
\hline & Detected defects \\
\hline
\end{tabular}

The inspection data can even be extended exploring other ECT capabilities. For instance, pulsed or multi-frequency excitation can be used to provide a certain visibility across the weld profile, high-resolution array probes may be used to pinpoint defects on bidimensional imaging results [18], local electrical conductivity and magnetic permeability [17] may reveal other relevant metallurgical properties as hardness/ ductility (potentially affected during preceding manufacturing steps).

\section{Conclusions}

A new pilot installation and ECT inspection system for laserbrazed welding is discussed in this paper. The proposed installation comprises a customized ECT probe, digital ECT instrumentation and a robotized arm enabling fully automated inspections. An absolute probe with a compensation mechanism allowed to maximize the signal-to-noise ratio (SNR)

Table 5 Comparison between the original destructive testing and the proposed inline ECT inspection

\begin{tabular}{|c|c|c|}
\hline Property & Original destructive testing & Inline ECT inspection \\
\hline Integration & Offline; postponed and potentially at different physical facilities & Inline; minimal floor plan changes and overhead \\
\hline Coverage & $\begin{array}{l}\text { Sampled; very low percentage of produced units, e.g. }<1 \% ; 10 \text { to } 20 \mathrm{~mm} \\
\text { spacing over the weld length }\end{array}$ & Full; $100 \%$ of produced units; $100 \%$ over the weld length \\
\hline Latency & High, hours to weeks & Very low, e.g. $<1 \mathrm{~s}$ \\
\hline Feedback & Impossible & Possible, e.g. to correct process deviations \\
\hline Traceability & None & Easy to implement, profits from VIN \\
\hline $\begin{array}{l}\text { Data } \\
\text { storage }\end{array}$ & Archived, hard to treat; unscalable & $\begin{array}{l}\text { Cloud-hosted database; easy to scale profiting from cloud } \\
\text { resources' elasticity }\end{array}$ \\
\hline Analytics & Very limited; classical statistics with high human effort & $\begin{array}{l}\text { Diversified state-of-the-art options: machine learning, big } \\
\text { data analytics }\end{array}$ \\
\hline Goal & $\begin{array}{l}\text { Detection of defects, provides very limited visibility over process } \\
\text { variations/evolution }\end{array}$ & Detection of defects and process monitoring and feedback \\
\hline
\end{tabular}


while preserving easy result interpretation when comparing to differential probes. The system was demonstrated on the detection of pore defects with $0.13 \mathrm{~mm}$ diameter and sub-surface defects buried $1 \mathrm{~mm}$ deep with high SNR. The operation with distinct frequencies allowed to distinguish between surface and sub-surface defects.

The integration of the proposed ECT inspection system and the laser-brazed welding process materializing an Industry 4.0-aligned quality control was also presented. Different outcomes will improve the process monitoring, and maintenance/ operations and final product quality while profiting from extended data gathered successively during production.

Funding This work was financially supported by the European Regional Development Fund (ERDF), Programa Operacional Regional de Lisboa (Lisb@2020 e Portugal2020) via the project PROBING (POCI-01-0247FEDER-040042, Ref. 40042). Authors acknowledge the Portuguese company INTROSYS - Integration for Robotic Systems (www. introsys.eu) for technical collaboration. MAM was financially supported by Fundação para a Ciência e a Tecnologia (FCT-MCTES) via the $\mathrm{PhD}$ scholarship FCT-SFRH/BD/108168/. LSR was financially supported by FCT-MCTES via the project EXPL/EEI-EEE/0394/2021. This work was also financially supported by FCT - MCTES via the project UIDB/00667/2020 (UNIDEMI).

Data availability Not applicable

Code availability Not applicable

\section{Declarations}

Ethics approval Not applicable

Consent to participate Not applicable

Consent for publication Not applicable

Conflict of interest The authors declare that they have no conflict of interest.

\section{Additional declarations for articles in life science journals that report the results of studies involving humans and/or animals Not applicable}

Open Access This article is licensed under a Creative Commons Attribution 4.0 International License, which permits use, sharing, adaptation, distribution and reproduction in any medium or format, as long as you give appropriate credit to the original author(s) and the source, provide a link to the Creative Commons licence, and indicate if changes were made. The images or other third party material in this article are included in the article's Creative Commons licence, unless indicated otherwise in a credit line to the material. If material is not included in the article's Creative Commons licence and your intended use is not permitted by statutory regulation or exceeds the permitted use, you will need to obtain permission directly from the copyright holder. To view a copy of this licence, visit http://creativecommons.org/licenses/by/4.0/.

\section{References}

1. Riedelsberger H (2006) Laser brazing in the automotive industry. 87th Fabtech / AWS Weld Show, Atlanta

2. Krishnaja D, Cheepu M, Venkateswarlu D (2018) A review of research progress on dissimilar laser weld-brazing of automotive applications. IOP Conf Ser Mater Sci Eng 330:012073. https:// doi.org/10.1088/1757-899X/330/1/012073

3. Frank S, Ungers M, Rolser R (2011) Coaxial control of aluminum and steel laser brazing processes. Phys Procedia 12:752-760. https://doi.org/10.1016/j.phpro.2011.03.094

4. Klocke F, Frank S (2013) Surface deposits in laser brazing. Sci Technol Weld Join 18:62-69. https://doi.org/10.1179/ 1362171812Y.0000000075

5. Wang W, Cai Y, Wang H-P, Carlson BE, Poss M (2020) Quality inspection scheme for automotive laser braze joints. Int $\mathrm{J}$ Adv Manuf Technol 106:1553-1566. https://doi.org/10.1007/s00170019-04779-8

6. Huang W, Kovacevic R (2012) Development of a real-time laserbased machine vision system to monitor and control welding processes. Int J Adv Manuf Technol 63:235-248. https://doi.org/10. 1007/s00170-012-3902-0

7. Senthil Kumar G, Natarajan U, Ananthan SS (2012) Vision inspection system for the identification and classification of defects in MIG welding joints. Int J Adv Manuf Technol 61:923-933. https://doi.org/10.1007/s00170-011-3770-Z

8. Ungers M, Fecker D, Frank S, Donst D, Märgner V, Abels P, Kaierle S (2010) In-situ quality monitoring during laser brazing. Phys Procedia 5:493-503. https://doi.org/10.1016/j.phpro.2010. 08.077

9. Grimm A, Schmidt M (2009) Possibilities for online process monitoring at laser brazing based on two dimensional detector systems. ICALEO:537-544

10. Duarte VR, Rodrigues TA, Machado MA, Pragana JPM, Pombinha $\mathrm{P}$, Coutinho L et al (2021) Benchmarking of nondestructive testing for additive manufacturing. 3D Print Addit Manuf 8:263-270. https://doi.org/10.1089/3dp.2020.0204

11. Machado MA, Rosado L, Pedrosa N, Miranda RM, Piedade M, Santos TG (2017) Customized eddy current probes for pipe inspection. Stud Appl Electromagn Mech 42:283-290. https://doi.org/10. 3233/978-1-61499-767-2-283

12. Machado MA, Antin K-N, Rosado LS, Vilaça P, Santos TG (2021) High-speed inspection of delamination defects in unidirectional CFRP by non-contact eddy current testing. Compos B Eng 224: 109167. https://doi.org/10.1016/j.compositesb.2021.109167

13. Machado MA, Rosado L, Pedrosa N, Vostner A, Miranda RM, Piedade M, Santos TG (2017) Novel eddy current probes for pipes: application in austenitic round-in-square profiles of ITER. NDT E Int 87:111-118. https://doi.org/10.1016/j.ndteint.2017.02.001

14. Sorger GL, Oliveira JP, Inácio PL, Enzinger N, Vilaça P, Miranda RM, Santos TG (2019) Non-destructive microstructural analysis by electrical conductivity: comparison with hardness measurements in different materials. J Mater Sci Technol 35:360-368. https://doi. org/10.1016/j.jmst.2018.09.047

15. Santos TG et al (2020) Reliability and NDT Methods. In: Torres Marques A, Esteves S, Pereira J, Oliveira L (eds) Additive Manufacturing Hybrid Processes for Composites Systems. Advanced Structured Materials, vol 129. Springer, Cham. https:// doi.org/10.1007/978-3-030-44522-5_8 
16. Santos TG, Vilaça P, Miranda RM (2011) Electrical conductivity field analysis for evaluation of FSW joints in AA6013 and AA7075 alloys. J Mater Process Technol 211:174-180. https://doi.org/10. 1016/j.jmatprotec.2010.08.030

17. Rodrigues NM, Rosado LS, Ramos PM (2017) A portable embedded contactless system for the measurement of metallic material conductivity and lift-off. Measurement 111:441-450. https://doi. org/10.1016/j.measurement.2017.05.002
18. Abrantes RF, Rosado LS, Piedade M, Ramos PM (2016) Pulsed eddy currents testing using a planar matrix probe. Measurement 77: 351-361. https://doi.org/10.1016/j.measurement.2015.09.026

19. Wesdyne. ELSCAN ${ }^{\mathrm{TM}}$ pipe and elbow scanner 2018. http:// amdataproducts.com/manual-scanners (accessed June 19, 2018).

Publisher's note Springer Nature remains neutral with regard to jurisdictional claims in published maps and institutional affiliations. 